\section{MERENJE EMISIJE BUKE MOTORNIH VOZILA NA TERITORIJI GRADA KRAGUJEVCA}

Branimir Đurić, master inž. mašinstva, Fakultet inženjerskih nauka, Univerzitet u Kragujevcu

Aleksandar Trifunović, master inž. saob., Saobraćajin fakultet, Univerzitet u Beogradu, a.trifunovic@sf.bg.ac.rs dr Svetlana Čičević, dipl. psiholog, Saobraćajni fakultet, Univerzitet u Beogradu, s.cicevic@sf.bg.ac.rs

\section{Anđela Josić, student}

Saobraćajin fakultet, Univerzitet u Beogradu, andjela.josic996@gmail.com Ivana Stokić, student

Saobraćajni fakultet, Univerzitet u Beogradu, ivanicas96@gmail.com

Stručni rad

Rezime: Buka u životnoj sredini definiše se kao buka koju stvaraju svi izvori, isključujući buku koja nastaje na samom radnom mestu u industrijskim pogonima. Buka u životnoj sredini je oduvek predstavljala veoma važan problem sa kojim se čovek suočavao i težio da njom upravlja $i$ da je kontroliše. Danas je problem mnogo izraženiji. Ogroman broj motornih vozila se kreće u urbanim gradskim sredinama, odnosno gradovima, kao i autoputevima. Teški kamioni sa dizel motorima i velikom bukom krstare putevima širom države. Avioni i vozovi takođe daju svoj doprinos povećanju ukupne buke.

Ključne reči: emisija buke, životna sredina, motorna vozila, putevi.

\section{MEASURING THE NOISE EMISSIONS OF MOTOR VEHICLES IN THE TERRITORY OF THE CITY KRAGUJEVAC - FEBRUARY 2018}

Branimir Đurić, M. Sc. M. E.

Faculty of Engineering Sciences, University of Kragujevac

Aleksandar Trifunović, M. Sc. T. E.,

Faculty of Traffic and Transport Engineering, University of Belgrade, a.trifunovic@sf.bg.ac.rs

\section{Svetlana Čičević, Ph. D. Psychologist,}

Faculty of Traffic and Transport Engineering, University of Belgrade, s.cicevic@sf.bg.ac.rs

Anđela Josić, student

Faculty of Traffic and Transport Engineering, University of Belgrade, andjela.josic996@gmail.com

Ivana Stokić, student

Faculty of Traffic and Transport Engineering, University of Belgrade, ivanicas96@gmail.com

Proffessional paper

Abstract: Noise emission in the environment is defined as noise which is produced by all sources, excluding noise which is produced at the workplace in industrial plants. Noise in the environment has always been a very important problem that a man faced and was trying to manage and control. Today, the problem is much more pronounced.
A huge number of motor vehicles are moving in urban areas, that is, cities, as well as in highways. Heavy trucks with diesel engines and high noise traveled roads across the country. Airplanes and trains also contribute to increasing total noise.

Key words: noise emission, the environment, motor vehicles, roads.

\section{UVOD}

Drumski saobraćaj predstavlja dominantan izvor povišenog nivoa buke na većem delu svih urbanih područja. Za praćenje stanja nivoa buke drumskog saobraćaja na karakterističnim lokacijama tokom godine potrebno je raspolagati odgovarajućom mernom strategijom, koja će obuhvatiti dinamičku prirodu procesa prostiranja zvuka, uticaj meteoroloških prilika na prostiranje zvuka, kao i ostale faktore koji su u funkciji utvrđivanja tačnog nivoa opterećenosti bukom datog mernog mesta na godišnjem nivou.

Budući da nacionalnom i Evropskom zakonskom regulativom nije propisan način određivanja godišnjih vrednosti indikatora buke u životnoj sredini, čije je poznavanje neophodno za kalibraciju strateških karata buke shodno Direktivi Evropske

Unije 2002/49/ES o proceni i upravljanju bukom u životnoj sredini, osnovni motiv za istraživanje u datoj oblasti upravo predstavlja pokušaj nalaženja adekvatne merne strategije za procenu dugotrajnih vrednosti indikatora buke u životnoj sredini.

Urbana gradska područja po svojim opštim karakteristikama, sadržaju i nameni pojedinih delova svoje teritorije, spadaju u kategoriju područja u kojima je stanje životne sredine narušeno pre svega sa stanovišta kvaliteta vazduha i buke.

Nivo buke, kao jedan od osnovnih pokazatelja kvaliteta životne sredine $u$ današnje vreme postaje sve ozbiljniji problem društvenih zajednica većih gradova širom sveta. Povećanju nivoa buke u gradskim sredinama doprinose brojni faktori. Jedan od njih je svakako stalni rast broja gradskog stanovništva, što doprinosi povećanju obima i inteziteta saobraćaja.

Buka se javlja kao značajan problem u čovekovoj okolini u većini gradskih urbanih područja. Ipak ovaj problem se još uvek ne shvata kao veoma važan, a samim tim mu se i ne posvećuje dovoljno pažnje uprkos činjenici da bitno utiče na kvalitet života ugrožene populacije. Razlog za ovakav pristup se može tražiti u samoj definiciji buke i njenoj percepciji kao subjektivnog doživljaja pojedinih spoljašnjih dešavanja, njenom specifičnom karakteru, kao i u teškoći povezivanja uzroka sa efektima koje se odražava na zdravlje ljudi. 
U izveštajima zdravstvenih organizacija navodi kao ozbiljna opasnost po zdravlje, sa posledicama koje se kreću u rasponu od uznemirenosti pa do smrtnog ishoda i smatra se jednim od indikatora stresa, koji ima psihosomatsku komponentu. Praktični efekti buke se kod ljudi najčešće manifestuju kao uznemirenost i razdražljivost, pad koncetracije, pogoršavanje kvaliteta sna i stres usled ishemije srca. Naročito je bitno razmatranje štetnog uticaja buke na zdravlje i razvoj dece, budući da doprinosi stvaranju govornih smetnji i utiče na smanjenu sposobnost dece za učenjem.

Istraživanja Svetske zdravstvene organizacije pokazuju da je više od 40 \% populacije država EU izloženo buci drumskog saobraćaja, čiji ekvivalentni nivo za period od čitavog dana premašuje 55 [dB], a da je čak $20 \%$ populacije izloženo ekvivalentnim nivoima većim od 65 [dB] za taj period. Ukoliko je poznato da buka nivoa iznad 55 [dB] sasvim izvesno izaziva neprijatnost, agresivno ponašanje i poremećaj sna, da stalna izloženost istoj iznad 65 [dB] može imati za posledicu hipertenziju (povišeni krvni pritisak), a da stalna izloženost iznad 75 [dB] izvesno utiče na povećanje nivoa stresa, povećane stope kardiovaskularnih oboljenja i potencijalni gubitak sluha, sasvim je sigurno da planiranje saobraćaja i zaštita stanovnika urbanih gradskih sredina od buke drumskog saobraćaja zahtevaju daleko ozbiljniji pristup. U skorije vreme su aktuelna istraživanja koja se pored zdravstvenih, bave i procenom ekonomskih posledica buke u životnoj sredini. Ovi podaci su dodatno podstakli istraživače u mnogim državama da se detaljno posvete izučavanju i definisanju problema buke drumskog saobraćaja.

\section{METODOLOGIJA RADA}

Istraživanje merenja saobraćajne buke je vršeno na 6 mernih mesta na području grada Kragujevca. Merne tačke su izabrane tako da omoguće prikazivanje stanja u različitim delovima naselja kao što su: centar naselja, glavne saobraćajnice, stambena zona, bolnička zona, zona odmora rekreacije, zona na granici sa industrijskom zonom. Lokacije na kojima je vršeno istraživanje su: Ulica Dragoslava Srejovića (kod predškolske ustanove), ugao ulica Kneza Mihaila i Kneza Miloša, ulica Kralja Aleksandra I Karađorđevića (gradski centar), ulica Kragujevačkog oktobra (Veliki park), ulica Neznanog junaka (naselje Aerodrom) i dvorište Kliničkog centra Kragujevac.

Istraživanje je rađeno $u$ mesecu februaru 2018.godine u dva dnevna, jednom večernjem i dva noćna termina u 15-minutnim intervalima. Merenje je vršeno pomoću mernog lanca (Slika 1.) čiji su parametri modularni analizator zvuka, kondenzatorski mikrofon i kalibrator.

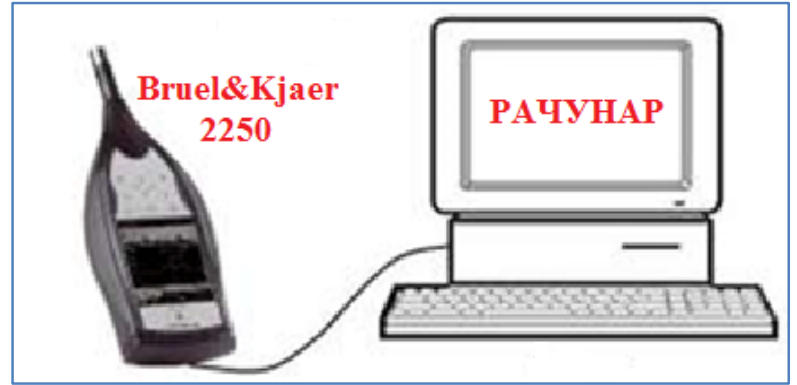

Slika 1. Prikaz mernog lanca

Kalibracija mernog lanca je vršena pre početka i na kraju merenja. Kondenzatorski mikrofon se nalazio na visini od 1.2 metra iznad tla i na udaljenosti većoj od 3.5 metara od objekata. Imajući u vidu pre svega ekonomska ograničenja, u ovom istraživanju se polazi od pretpostavke da je na osnovu rezultata dugotrajnog permanentnog monitoringa buke, uzimajući u obzir sve faktore koji mogu da utiču na rezultate merenja, moguće primenom metoda višekriterijumskog odlučivanja izvršiti izbor merne strategije sa optimalnom dužinom intervala merenja koja bi zadovoljila polazni zahtev da uz minimalno trajanje angažovanja merne opreme mogu da se obezbede dovoljno tačni i precizni rezultati za procenu godišnjih vrednosti indikatora buke u životnoj sredini na svim mernim mestima istog karaktera. Vrednosti kriterijumskih funkcija pokazuju koliko razmatrani sistem odgovara datim alternativama sistema. Optimizacija postupka izbora merne strategije treba da predstavlja određivanje rešenja koje je najbolje prema definisanim kriterijumima i koje zadovoljava sva data ograničenja.

U Tabeli 1. prikazani su uslovi ispitivanja koji su na mernom mestu koji su zadovoljili zahteve kvaliteta.

Tabela 1. Uslovi ispitivanja

\begin{tabular}{|l|c|c|c|}
\hline \multicolumn{1}{|c|}{$\begin{array}{c}\text { Parametri } \\
\text { okruženja }\end{array}$} & $\begin{array}{c}\text { Dnevno } \\
\text { merenje }\end{array}$ & $\begin{array}{c}\text { Večernje } \\
\text { merenje }\end{array}$ & $\begin{array}{c}\text { Noćno } \\
\text { merenje }\end{array}$ \\
\hline Temperatura: & $8^{\circ} \mathrm{C}$ & $3^{\circ} \mathrm{C}$ & $-1^{\circ} \mathrm{C}$ \\
Vlaž. Vazduha: & $72 \%$ & $76 \%$ & $80 \%$ \\
Pritisak: & $1009 \mathrm{hPa}$ & $1008 \mathrm{hPa}$ & $1006 \mathrm{hPa}$ \\
Brzina vetra: & $0.5 \mathrm{~m} / \mathrm{s}$ & $0.5 \mathrm{~m} / \mathrm{s}$ & $0.5 \mathrm{~m} / \mathrm{s}$ \\
Oblačno: & $\checkmark$ & $\checkmark$ & $\checkmark$ \\
\hline
\end{tabular}

Cilj ovog rada je definisanje stanja nivoa buke na karakterističnim lokacijama na teritoriji grada Kragujevca i predstavlja proces koji podrazumeva uočavanje dominantnih izvora buke i praćenje relevantnih akustičnih i metereoloških veličina $u$ određenom vremenskom periodu na datim lokacijama. 
Svakako najefektivniji pristup datom problemu predstavlja dugotrajni, u ovom slučaju permanentnikontinualni godišnji monitoring buke na lokacijama od interesa, budući da izrada strateške karte buke kao osnovnog dokumenta za analizu stanja buke predviđa poznavanje opterećenosti bukom datog prostora na godišnjem nivou. Međutim, složenost ovakvog pristupa $\mathrm{i}$ njegova velika zahtevnost $u$ pogledu angažovanja neophodnih resursa - ljudskih i materijalnih, dovodi do potrebe za pronalaženjem efikasnijih metoda za određivanje godišnjih vrednosti indikatora buke $L_{\text {den }}$ i Lnight na datoj lokaciji, čije bi procenjene vrednosti u zadovoljavajućoj meri odgovorale vrednostima koje su dobijene dugotrajnim merenjem. $U$ tom smislu, opšti cilj istraživanja predstavlja pronalaženje optimalne mere strategije kojom bi se na osnovu jednokratnog merenja u mernom intervalu znatno kraćem od godinu dana, dobili rezultati koji bi sa prihvatljivom tačnošću i preciznošću prezentovali pravo stanje buke na datim lokacijama na teritoriji grada Kragujevca na godišnjem nivou. Posebni ciljevi predmetnog istraživanja predstavljaju ispitivanje mogućnosti primene poznatih strategija za procenu vrednosti godišnjih indikatora buke u životnoj sredini u domaćem okruženju, kao i implementaciju postignutih rezultata, diskusija i zaključaka u ovom radu prilikom formiranja pre svega nacionalnih propisa iz date oblasti, kao i potencijalni doprinos standardizaciji određivanja dugotrajnih vrednosti indikatora buke u životnoj sredini.

\section{PRIKAZ REZULTATA RADA SA DISKUSIJOM}

Reprezentativne veličine za ocenu stanja buke na izabranim deonicama na teritoriji grada Kragujevca na godišnjem nivou su prema Direktivi 2002/49/ES vrednosti godišnjih indikatora buke $L_{\text {den }}$ i $L_{n i g h t . ~} U$ tom smislu promenljivost emisije buke izvora i metereoloških parametara tokom godine, kako god da utiču na prostiranje zvuka, moraju biti uzeti u obzir prilikom utvrđivanja vrednosti pomenutih veličina, bilo da se radi o postupku utvrđivanja metodom merenja, odnosno dugotrajnim kontinualnim monitorongom, ili metodom procene njihove vrednosti na osnovu merenja u kraćim vremenskim intervalima. Karakteristike dugotrajnog monitoringa eliminišu ovaj postupak za slučaj masovne primene, tako da se zbog toga primenjuje tehnika polupermanentnog monitoringa pomoću koje se vrši procena godišnjih vrednosti indikatora buke na osnovu izmerenih vrednosti u kraćim vremenskim periodima izabranim $u$ toku godine. Tačnost procenjenih vrednosti zavisi od dužine vremenskog intervala merenja polupermanentnog monitoringa, kao i kod promenljivosti emisije buke na mestu prijema, koja uključuje vremensku promenljivost emisije izvora i uticaja metereoloških parametara na prostiranje zvuka.
Pored toga što evropski propisi ne raspolažu metodologijom za procenu vrednosti ekvivalentnog godišnjeg nivoa buke u životnoj sredini na osnovu polupermanentnih merenja, dosadašnji rezultati velikog broja realizovanih eksperimentalnih istraživanja u svetu, upućuju na mogućnost iznalaženja prihvatljivog modela i strategije za realizaciju datog problema.

U istraživanju se polazi od pretpostavke da je planiranom metodologijom moguće odrediti optimalnu dužinu intervala merenja na osnovu koje će se sa tačnošću od 1.5 [dB] i preciznošću od 1 [dB] biti izvršena procena dugotrajnih godišnjih indikatora buke na posmatranim lokacijama na teritoriji grada Kragujevca, dominantno opterećenih bukom drumskog saobraćaja. Zahtevana tačnost podrazumeva da se nijedna vrednost bilo kog od izmerenih indikatora buke nekom od strategija polupermanentnog monitoringa $u$ apsolutnom iznosu ne razlikuje za više od $1.5[\mathrm{~dB}]$ od stvarne prave vrednosti indikatora buke dobijene dugotrajnim permanentnim monitoringom. Postavljen zahtev za preciznošću od $1[\mathrm{~dB}]$ podrazumeva da vrednost standardne devijacije rezultata merenja bilo kog od izmerenih indikatora buke nekom od strategija polupermanentnog monitoringa ne bude veća od 1 [dB]. Rezultat formiranog modela bi trebalo da predstavlja njegovu preporuku za izbor optimalne strategije merenja sa stanovišta dobijanja zadovoljavajućih rezultata. $\mathrm{Na}$ kraju bi trebalo napomenuti da uporednom analizom pojedinih strategija, za krajnji rezultat istraživanja se očekuje donošenje opšte strategije kratkotrajnih merenja, koja bi važila za bilo koje merno mesto sličnih karakteristika i omogućila procenu vrednosti godišnjih indikatora buke u životnoj sredini sa zadovoljavajućom preciznošću.

Da bi se procenila reakcija ljudi na dugotrajno uznemiravanje bukom sa nekom od ovih posebnih karakteristika, na $\mathrm{A}$ - ponderisani ekvivalentni nivo dodaje se korekcija u decibelima. Merodavni nivo ukupne buke se koristi kao osnovni indikator za ocenu uznemiravanja bukom i poređenje sa graničnim vrednostima. Vrste buke za koje se računa merodavni nivo ukupne buke su ujednačena, kontinualno promenljiva, isprekidana, izolovani impuls zvučne energije, kvaziimpulsna i pojedinačni i ponovljivi pojedinačni događaji. Preporuke za merenje različitih vrsta buke prikazane su Tabelom 3.

Granične vrednosti indikatora buke $u$ naseljenim mestima, prema zonama naselja, prikazane su u Tabeli 2. Granične vrednosti se odnose na ukupnu buku koja potiče od svih izvora, a utvrđuje se osnovnim indikatorima ili merodavnim nivoom buke. 
Tabela 2. Granične vrednosti indikatora buke na otvorenom prostoru

\begin{tabular}{|c|c|c|}
\hline \multirow[t]{2}{*}{ Namena prostora } & \multicolumn{2}{|c|}{ Nivo buke [dB] } \\
\hline & Dan i veče & Noć \\
\hline $\begin{array}{l}\text { Područja za odmor i rekreaciju, } \\
\text { Bolničke zone i oporavilišta, } \\
\text { Kulturno-istorijski lokaliteti, } \\
\text { Veliki parkovi }\end{array}$ & 50 & 40 \\
\hline $\begin{array}{l}\text { Turistička područja, } \\
\text { Kampovi, } \\
\text { Školske zone }\end{array}$ & 50 & 45 \\
\hline Čisto stambena područja & 55 & 45 \\
\hline $\begin{array}{l}\text { Poslovno-stambena područja, } \\
\text { Trgovačko-stambena područja, } \\
\text { Dečja igrališta }\end{array}$ & 60 & 50 \\
\hline $\begin{array}{l}\text { Gradski centar, } \\
\text { Zanatska i trgovačka zona, } \\
\text { Administrativno-upravna zona } \\
\text { sa stanovima, } \\
\text { Zona duž autoputeva, } \\
\text { Zona duž magistralnih i } \\
\text { gradskih saobraćajnica }\end{array}$ & 65 & 55 \\
\hline $\begin{array}{l}\text { Industrijska zona, } \\
\text { Skladišna i servisna područja } \\
\text { bez stambenih zgrada, } \\
\text { Transportni terminali bez } \\
\text { stambenih zgrada }\end{array}$ & \multicolumn{2}{|c|}{$\begin{array}{l}\text { Buka na granici ove zone } \\
\text { ne sme da prelazi graničnu } \\
\text { vrednost u zoni sa kojom se } \\
\text { graniči }\end{array}$} \\
\hline
\end{tabular}

Tabela 3. Preporuke za merenje različitih vrsta buke

\begin{tabular}{|c|c|c|c|c|c|c|c|c|}
\hline $\begin{array}{l}\text { Ekvivalentni nivo } \\
\text { buke } \text { LAeq }^{-}\end{array}$ & (B) & () & (B) & (B) & (B) & (C) & ® & (C) \\
\hline $\begin{array}{l}\text { Nivo izloženosti } \\
\text { zvuku } L_{E}\end{array}$ & (C) & (C) & (C) & (C) & (C) & (B) & (C) & (B) \\
\hline Vremenski tok & $\bar{P}$ & (B) & (B) & (R) & (B) & P & (B) & P \\
\hline Procentni nivo & (C) & (B) & (B) & (R) & (B) & (C) & (C) & (C) \\
\hline $\begin{array}{l}\text { Frekvencijska } \\
\text { analiza }\end{array}$ & (R) & (®) & (B) & (R) & ( & (C) & (C) & P \\
\hline Vreme merenja & $\begin{array}{c}5 \\
\min \end{array}$ & 1) & 2) & 3) & 4) & 5) & 6) & 7) \\
\hline $\begin{array}{l}\text { Legenda: } \\
\text { ®- obavezno } \\
\text { P } \\
\text { preporučuje se } \\
\text { @ - nije } \\
\text { obavezno }\end{array}$ & \multicolumn{8}{|c|}{$\begin{array}{ll}\text { (1) } & \text { - ujednačena buka } \\
\text { (2) } & \text { - kontinualno periodično promenljiva } \\
& \text { buka } \\
\text { (3) } & \text { - kontinualno neperiodično promenljiva } \\
& \text { buka } \\
\text { (4) } & \text { - isprekidana buka sa intervalima } \\
& \text { ujednačene buke } \\
\text { (5) } & \text { - isprekidana buka sa intervalima } \\
& \text { promenljive buke } \\
\text { (6) } & \text { - izolovani impuls zvučne energije } \\
\text { (7) } & \text { - kvaziimpulsna buka } \\
\text { (8) } & \text { - pojedinačni ili ponovljivi pojedinačni } \\
& \text { događaji }\end{array}$} \\
\hline \multicolumn{9}{|c|}{$\begin{array}{l}\text { 1)Vreme merenja treba da obuhvati bar tri perioda rada specifičnog izvora. } \\
\text { 2)Najmanje dva } 15 \text {-minutna merna intervala u dnevnom periodu, jedan u } \\
\text { večernjem i dva u noćnom periodu. Kod monitoringa buke broj 15-minutnih } \\
\text { mernih intervala može biti i veći i on se određuje programom monitoringa. } \\
\text { Takođe, monitoring buke može da se vrši i neprekidno } 24 \text { sata, ukoliko se } \\
\text { raspolaže adekvatnom mernom opremom. } \\
\text { 3)Merni interval } 5 \text { minuta u periodu kada je buka ujednačena. } \\
\text { 4)U periodima kada je buka promenljiva primenjuje se 2) } \\
\text { 5)Trajanje izolovanog impulsa zvučne energije. } \\
\text { 6)Ako je nivo impulsa ujednačen primenjuje se napomena pod 1). Ako je } \\
\text { nivo impulsa promenljiv primenjuje se napomena pod 2) } \\
\text { 7)Trajanje pojedinačnih događaja. }\end{array}$} \\
\hline
\end{tabular}

Akustičke karakteristike buke mogu biti vremenska i frekvencijska. Vremenska buka može biti nepromenljiva, promenljiva, isprekidana i impulsna. Dok je frekvencijska širokopojasna, uskopojasna, sa istaknutim tonom, sa niskofrekventnim sadržajem. Rezultati nivoa buke za svako pojedinačno merno mestu prikazano je Tabelama 5, 6, 7, 8, 9 i 10.

Tabela 4. Rezultati nivoa buke na mernom mestu 1 (Ulica Dragoslava Srejovića - kod predškolske ustanove)

\begin{tabular}{|c|c|c|c|c|}
\hline & & \multicolumn{3}{|c|}{ Ekvivalentni nivo $\mathrm{dB}(\mathrm{A})$} \\
\hline & & $\begin{array}{l}\text { Izmereni } \\
\text { nivo }\end{array}$ & $\begin{array}{l}\text { Merodavni } \\
\text { nivo }\end{array}$ & $\begin{array}{l}\text { Dozvoljeni } \\
\text { nivo }\end{array}$ \\
\hline \multirow{2}{*}{ DAN } & $\begin{array}{l}10: 30 \\
- \\
10: 45\end{array}$ & 62,4 & 62 & 65 \\
\hline & $\begin{array}{l}15: 30 \\
- \\
15: 45\end{array}$ & 62,6 & 63 & 65 \\
\hline VEČE & $\begin{array}{l}18: 30 \\
- \\
18: 45\end{array}$ & 58,4 & 58 & 65 \\
\hline \multirow{2}{*}{ NOĆ } & $\begin{array}{l}22: 30 \\
- \\
22: 45\end{array}$ & 54,6 & 55 & 55 \\
\hline & $\begin{array}{l}01: 30 \\
- \\
01: 45\end{array}$ & 54,2 & 54 & 55 \\
\hline
\end{tabular}

Kao što je Tabelom 4. prikazano merodavni nivoi buke ispitanih zvučnih izvora ne prelaze dozvoljeni nivo za zonu duž glavnih gradskih saobraćajnica (za dan i veče, maksimalni dozvoljeni nivo $65 \mathrm{~dB}(\mathrm{~A})$ ) i za noć (maksimalni dozvoljeni nivo $55 \mathrm{~dB}(\mathrm{~A})$ ).

Za merno mesto 1 utvrđeno je da je akustična vremenska karakteristika promenljiva jer je tokom merenja, promena nivoa buke pri pokazivanju „sporo“ pokazala kolebanje veće od $5 \mathrm{~dB}(\mathrm{~A})$, pa je zbog toga buka promenljiva. Dok je frekvencijska širokopojasna i spektralnom analizom je utvrđeno da je raspodela zvučne energije u više susednih oktava ravnomerna.

Tabela 5. Rezultati nivoa buke na mernom mestu 2 (Ugao ulica Kneza Mihaila I Kneza Miloša)

\begin{tabular}{|c|c|c|c|c|}
\hline & \multicolumn{3}{|c|}{ Ekvivalentni nivo $\mathrm{dB}(\mathrm{A})$} \\
\hline & & $\begin{array}{l}\text { Izmereni } \\
\text { nivo }\end{array}$ & $\begin{array}{l}\text { Merodavni } \\
\text { nivo }\end{array}$ & $\begin{array}{l}\text { Dozvoljeni } \\
\text { nivo }\end{array}$ \\
\hline \multirow{2}{*}{ DAN } & $\begin{array}{l}11: 00 \\
- \\
11: 15\end{array}$ & 62,4 & 62 & 65 \\
\hline & $\begin{array}{l}16: 00 \\
- \\
16: 15\end{array}$ & 63,1 & 63 & 65 \\
\hline VEČE & $\begin{array}{l}19: 00 \\
- \\
19: 15\end{array}$ & 58,3 & 58 & 65 \\
\hline \multirow{2}{*}{ NOĆ } & $\begin{array}{l}23: 00 \\
- \\
23: 15\end{array}$ & 53,4 & 53 & 55 \\
\hline & $\begin{array}{l}02: 00 \\
- \\
02: 15\end{array}$ & 53,7 & 54 & 55 \\
\hline
\end{tabular}


Prikazano Tabelom 5. merodavni nivoi buke ispitanih zvučnih izvora ne prelaze dozvoljeni nivo za zonu gradski centar (za dan i veče, maksimalni dozvoljeni nivo $65 \mathrm{~dB}(\mathrm{~A})$ ) i za noć (maksimalni dozvoljeni nivo $55 \mathrm{~dB}(\mathrm{~A}))$. Za merno mesto 2 utvrđeno je da je akustična vremenska karakteristika promenljiva jer je tokom merenja, promena nivoa buke pri pokazivanju „sporo“ pokazala kolebanje veće od $5 \mathrm{~dB}(\mathrm{~A})$, pa je zbog toga buka promenljiva. Dok je frekvencijska širokopojasna i spektralnom analizom je utvrđeno da je raspodela zvučne energije $u$ više susednih oktava ravnomerna

Tabela 6. Rezultati nivoa buke na mernom mestu 3 (Ulica Kralja Aleksandra I Karađorđevića (gradski centar))

\begin{tabular}{|c|c|c|c|c|}
\hline & \multicolumn{3}{|c|}{ Ekvivalentni nivo $\mathrm{dB}(\mathrm{A})$} \\
\hline & & $\begin{array}{c}\text { Izmereni } \\
\text { nivo }\end{array}$ & $\begin{array}{l}\text { Merodavni } \\
\text { nivo }\end{array}$ & $\begin{array}{l}\text { Dozvoljeni } \\
\text { nivo }\end{array}$ \\
\hline \multirow{2}{*}{ DAN } & $\begin{array}{l}12: 30 \\
- \\
12: 45\end{array}$ & 54,6 & 55 & 55 \\
\hline & $\begin{array}{l}17: 30 \\
- \\
17: 45\end{array}$ & 53,3 & 53 & 55 \\
\hline VEČE & $\begin{array}{l}20: 30 \\
- \\
20: 45\end{array}$ & 48,4 & 48 & 55 \\
\hline \multirow{2}{*}{ NOĆ } & $\begin{array}{l}00: 30 \\
\overline{00: 45}\end{array}$ & 44,1 & 44 & 45 \\
\hline & $\begin{array}{l}03: 30 \\
- \\
03: 45\end{array}$ & 43,8 & 44 & 45 \\
\hline
\end{tabular}

Prikazano Tabelom 6. merodavni nivoi buke ispitanih zvučnih izvora ne prelaze dozvoljeni nivo za zonu čisto stambeno područje (za dan i veče, maksimalni dozvoljeni nivo $55 \mathrm{~dB}(\mathrm{~A})$ ) i za noć (maksimalni dozvoljeni nivo $45 \mathrm{~dB}(\mathrm{~A})$ ). Vremenska karakteristika je nepromenljiva jer je tokom merenja, promena nivoa buke pri pokazivanju „sporo“ nije pokazala kolebanje veće od $5 \mathrm{~dB}(\mathrm{~A})$. $A$ frekvencijska je širokopojasna zbog spektralne analize kojom je utvrđeno da je raspodela zvučne energije u više susednih oktava ravnomerna.

Tabela 7. Rezultati nivoa buke na mernom mestu 4 (Ulica Kragujevačkog oktobra (Veliki park))

\begin{tabular}{|c|c|c|c|c|}
\hline & \multicolumn{3}{|c|}{ Ekvivalentni nivo $\mathrm{dB}(\mathrm{A})$} \\
\hline & & $\begin{array}{l}\text { Izmereni } \\
\text { nivo }\end{array}$ & $\begin{array}{l}\text { Merodavni } \\
\text { nivo }\end{array}$ & $\begin{array}{l}\text { Dozvoljeni } \\
\text { nivo }\end{array}$ \\
\hline \multirow{2}{*}{ DAN } & $\begin{array}{l}10: 00- \\
10: 15\end{array}$ & 54 & 54 & 55 \\
\hline & $\begin{array}{l}15: 00- \\
15: 15\end{array}$ & 53,2 & 53 & 55 \\
\hline VEČE & $\begin{array}{l}18: 00- \\
18: 15\end{array}$ & 49,6 & 50 & 55 \\
\hline \multirow{2}{*}{ NOĆ } & $\begin{array}{l}22: 00- \\
22: 15\end{array}$ & 43,7 & 44 & 45 \\
\hline & $\begin{array}{l}01: 00- \\
01: 15\end{array}$ & 42,8 & 43 & 45 \\
\hline
\end{tabular}

U Tabeli 7. merodavni nivoi buke ispitanih zvučnih izvora ne prelaze dozvoljeni nivo za zonu čisto stambeno područje (za dan i veče, maksimalni dozvoljeni nivo $55 \mathrm{~dB}(\mathrm{~A})$ ) i za noć (maksimalni dozvoljeni nivo $45 \mathrm{~dB}(\mathrm{~A})$ ). Vremenska karakteristika je nepromenljiva jer je tokom merenja, promena nivoa buke pri pokazivanju „sporo“ nije pokazala kolebanje veće od $5 \mathrm{~dB}(\mathrm{~A})$. A frekvencijska je širokopojasna zbog spektralne analize kojom je utvrđeno da je raspodela zvučne energije u više susednih oktava ravnomerna.

Tabela 8. Rezultati nivoa buke na mernom mestu 5 (Ulica Neznanog junaka (naselje Aerodrom))

\begin{tabular}{|c|c|c|c|c|}
\hline & \multicolumn{3}{|c|}{ Ekvivalentni nivo dB(A) } \\
\hline & & $\begin{array}{l}\text { Izmereni } \\
\text { nivo }\end{array}$ & $\begin{array}{l}\text { Merodavni } \\
\text { nivo }\end{array}$ & $\begin{array}{l}\text { Dozvoljeni } \\
\text { nivo }\end{array}$ \\
\hline \multirow{2}{*}{ DAN } & $\begin{array}{l}12: 00- \\
12: 15\end{array}$ & 54,2 & 54 & 50 \\
\hline & $\begin{array}{l}17: 00- \\
17: 15\end{array}$ & 54 & 54 & 50 \\
\hline VEČE & $\begin{array}{l}22: 00- \\
22: 15\end{array}$ & 46,8 & 47 & 50 \\
\hline \multirow{2}{*}{ NOĆ } & $\begin{array}{l}00: 00- \\
00: 15\end{array}$ & 43,2 & 43 & 40 \\
\hline & $\begin{array}{l}\text { 03:00 - } \\
03: 15\end{array}$ & 43,4 & 43 & 40 \\
\hline
\end{tabular}

U Tabeli 8. merodavni nivoi buke ispitanih zvučnih izvora ne prelaze dozvoljeni nivo za bolničke zone i oporavilišta (za dan i veče, maksimalni dozvoljeni nivo $50 \mathrm{~dB}(\mathrm{~A})$ ) i za noć (maksimalni dozvoljeni nivo $40 \mathrm{~dB}(\mathrm{~A}))$. Vremenska karakteristika je promenljiva jer je tokom merenja, promena nivoa buke pri pokazivanju „sporo“ pokazala kolebanje veće od 5 $\mathrm{dB}(\mathrm{A})$. A frekvencijska je širokopojasna zbog spektralne analize kojom je utvrđeno da je raspodela zvučne energije u više susednih oktava ravnomerna.

Tabela 9. Rezultati nivoa buke na mernom mestu 6 (Dvorište Kliničkog centra Kragujevac)

\begin{tabular}{|c|l|c|c|c|}
\cline { 3 - 5 } \multicolumn{2}{c|}{} & \multicolumn{3}{c|}{ Ekvivalentni nivo dB(A) } \\
\cline { 3 - 5 } \multicolumn{2}{c|}{} & $\begin{array}{c}\text { Izmereni } \\
\text { nivo }\end{array}$ & $\begin{array}{c}\text { Merodavni } \\
\text { nivo }\end{array}$ & $\begin{array}{c}\text { Dozvoljeni } \\
\text { nivo }\end{array}$ \\
\hline \multirow{4}{*}{ DAN } & $\begin{array}{l}11: 30- \\
11: 45\end{array}$ & 52,3 & 52 & 50 \\
\cline { 2 - 5 } & $\begin{array}{l}16: 30- \\
16: 45\end{array}$ & 52,5 & 53 & 50 \\
\hline \multirow{2}{*}{ VEČE } & $\begin{array}{l}19: 30- \\
19: 45\end{array}$ & 49,2 & 49 & 50 \\
\hline \multirow{4}{*}{ NOĆ } & $\begin{array}{l}23: 30- \\
23: 45\end{array}$ & 43,7 & 44 & 40 \\
\cline { 2 - 5 } & $\begin{array}{l}\mathbf{0 2 : 3 0 -} \\
02: 45\end{array}$ & 42,6 & 43 & 40 \\
\hline
\end{tabular}


Tabelom 9. predstavljeni merodavni nivoi buke ispitanih zvučnih izvora ne prelaze dozvoljeni nivo za zonu odmora i rekreacije (za dan i veče, maksimalni dozvoljeni nivo $50 \mathrm{~dB}(\mathrm{~A}))$ i za noć (maksimalni dozvoljeni nivo $40 \mathrm{~dB}(\mathrm{~A})$ ). Vremenska karakteristika je promenljiva jer je tokom merenja, promena nivoa buke pri pokazivanju „sporo“ pokazala kolebanje veće od $5 \mathrm{~dB}(\mathrm{~A})$. A frekvencijska je širokopojasna zbog spektralne analize kojom je utvrđeno da je raspodela zvučne energije u više susednih oktava ravnomerna.

\section{LITERATURA}

[1] Abbaspour M., Golmohammadi R., Nassiri P. and Mahjub $H$.: „An investigation on time-interval optimisation of traffic noise measurement", Research note, Journal of Low Frequency Noise, Vibration and Active Control, 25(4), 267-273, 2006

[2] Bengtsson J. and Waye P.K.: „Assessments of low frequency noise complaints among the local Environmental Health Authorities and a follow-up study 14 years later", Journal of Low Frequency Noise, Vibration and Active Control, 22(1), 9-16, 2003

[3] Berglund B., Lindvall T., Schwela H.D.: „Guidelines for Community Noise", World Health Organization (WHO) document, London, 1999

[4] Berglund, B.; Lindvall, T.: „Community Noise”, Archives of the Center for Sensory Research, Vol. 2, Issue 1 , Stockholm University and Karolinska Institute, Stockholm, 1995

[5] Bhusari P. and Asutkar G.M.: "Design of noise pollution monitoring system using wireless sensor network", International Journal of Software and Web Sciences, 13(220), 55-57, 2013

[6] BIMP/IEC/IFCC/ISO/IUPAP/OIML: „GUM - Guide to the Expression of Uncertainty in Measurements", International Organisation for Standardisation, Geneva, Switzerland, 1995 